\title{
Mutations in rpoB and $k a t G$ genes in Mycobacterium isolates from the Southeast of Mexico
}

\author{
R Zenteno-Cuevas ${ }^{1 /}{ }^{+}$, JC Zenteno ${ }^{3}$, A Cuellar ${ }^{4}$, B Cuevas $^{1,2}$, CL Sampieri', JE Riviera ${ }^{4}$, A Parissi $^{4}$ \\ ${ }^{1}$ Laboratorio de Ecología y Salud, Instituto de Salud Pública 2Doctorado en Ciencias Biomédicas, Universidad Veracruzana, \\ Av. Luis Castelazo Ayala s/n, AP 57, CP 91190, Xalapa, Veracruz, México ${ }^{3}$ Departamento de Genética, Instituto de Oftalmología, \\ Conde de Valenciana, México DF, México ${ }^{4}$ Laboratorio Estatal de Salud Pública, Servicios de Salud de Veracruz, Veracruz, México
}

The most frequent mutations associated with rifampin and isoniazid resistance in Mycobacterium are the substitutions at codons 531 and 315 in the $\mathrm{rpoB}$ and $\mathrm{katG}$ genes, respectively. Hence, the aim of this study was to characterize these mutations in Mycobacterium isolates from patients suspected to be infected with drug-resistant (DR) pulmonary tuberculosis (TB) in Veracruz, Mexico. Drug susceptibility testing of 25 clinical isolates revealed that five were susceptible while 20 (80\%) were DR (15\% of the annual prevalence for Veracruz). Of the DR isolates, 15 (75\%) were resistant to rifampin, 17 (85\%) to isoniazid and 15 (75\%) were resistant to both drugs (MDR). Sequencing analysis performed in the isolates showed that 14 (93\%) had mutations in the rpoB gene; seven of these (47\%) exhibited a mutation at $531(S \rightarrow L)$. Ten (58\%) of the 20 resistant isolates showed mutations in katG; nine (52\%) of these 10 exhibited a mutation at $315(S \rightarrow T)$. In conclusion, the DR profile of the isolates suggests a significant number of different DR-TB strains with a low frequency of mutation at codons 531 and 315 in $\mathrm{rpoB}$ and $\mathrm{katG}$, respectively. This result leads us to consider different regions of the same genes, as well as other genes for further analysis, which is important if a genetic-based diagnosis of DR-TB is to be developed for this region.

Key words: tuberculosis - rifampin - isoniazid - mutations

Tuberculosis (TB) still remains a major public health problem worldwide, especially in developing countries, with approximately eight million new infections and 2,5 million deaths per year (Dye et al. 1999).

Since the resurgence of TB in the mid-1980s, an increasing number of drug-resistant (DR) Mycobacterium tuberculosis strains have developed throughout the world. The last decade has seen a particular increase in the occurrence of drug-resistant (DR-TB) and multi-DR strains [resistant to rifampin ( Rif $^{\mathrm{r}}$ ) and isoniazid $\left(\mathrm{Iso}^{\mathrm{r}}\right)$ MDR-TB]. This resurgence has threatened short-course TB chemotherapy (WHO 2006) and is a growing global public health concern (Zumia \& Grange 2001). A major point of concern is that patients infected with DR-TB and multidrug-resistant TB (MDR-TB) strains are more difficult to treat and are more likely to remain as sources of infection for longer periods of time than patients with drug-susceptible strains (Zumia \& Grange 2001).

Drug resistance in $M$. tuberculosis is caused by mutations in conserved regions of the genome (Musser 1995, Zhang \& Telenti 2000). Rif is mainly caused by mutations in the $\beta$ subunit of RNA polymerase, which is encoded by the rроB gene. More than $95 \%$ of resistant strains harbour mutations within the Rifampin Resistant

\footnotetext{
Financial support: National Council for Science and Technology (Fondo Sectorial: CONACYT-SALUD, 2005-02-14380), POA-UV 2007-2008. BCC is a CONACYT Doctoral fellowship (171183). + Corresponding author: rzenteno@uv.mx

Received 18 September 2008

Accepted 28 January 2009
}

Determining Region (RRDR), an 81-bp hot-spot region (codons 507 to 533) of rpoB. In contrast, Iso is controlled by a more complex genetic system that involves more than one gene, but the most common mutations are associated with $k a t G$ and the mabA-inhA intergenic region (Musser 1995, Zhang \& Telenti 2000).

In 2006, the rates of morbidity and mortality of TB in Mexico was estimated to be 14 and 2.5 cases per 100,000 people, respectively. In the same year, the state of Veracruz, in the Southeast of Mexico, reported 1,800 TB cases resulting in 250 deaths among its population of seven million inhabitants; this state is considered one of the largest contributors of the disease. Information regarding the evolution of DR-TB and MDR-TB in Mexico is scarce, with the last survey from 1997 showing that $21 \%$ and $7 \%$ of isolates were DR-TB and MDR-TB, respectively (Granich et al. 2000). In 2007, 541 DR-TB cases were reported in Mexico, with 105 (20\%) originating in Veracruz, placing this region among the main sources of these isolates. Unfortunately, no official data regarding MDR-TB was recorded (Programa estatal de tuberculosis 2008). The 2008 DR-TB and MDR-TB survey will provide a better understanding of the extent of this health problem in Mexico (National Survey on TB drug resistance 2008).

The frequency of mutations related to rpoB and $k a t G$ in DR-TB strains vary widely around the world (Zhang \& Telenti 2000). Unfortunately, information about the frequency and distribution of the mutations in DR-TB strains in Mexico is limited (Alvarado et al. 2001, Bobadilla del Valle et al. 2001, Viader-Salvado et al. 2003, Ramaswamy et al. 2004). Thus, we propose to explore the molecular patterns of mutations in $r p o B$ and $k a t G$ genes of sensitive and drug resistant mycobacteria strains obtained from patients experiencing pulmonary symptoms of TB. 


\section{MATERIALS AND METHODS}

Clinical samples and Mycobacterium susceptibility test - From February-July of 2007, 72 expectorations were collected from 25 patients suspected to be afflicted with DR-TB. On account of the results of their drug susceptibility tests, those patients were referred to the Public Health Laboratory by the Health Services of Veracruz, Mexico. This laboratory receives samples from the entire state and is the reference centre for TB diagnoses and DR susceptibility tests. Sample decontamination was performed according to Petroff's method, and Löwenstein-Jensen slants medium was used for primary isolation. Susceptibility testing for the first line drugs $\mathrm{Iso}^{\mathrm{r}}$, streptomycin, Rif', ethambutol and pyrazinamide was performed in duplicate according to the radiometric method (BACTEC 460, Becton-Dickinson, Sparks, MD).

DNA purification and specie determination - Genomic DNA from each clinical strain was prepared using the sodium chloride, c-ethyl-trimethylammonium bromide and phenol-chloroform method (Sambrook et al. 1989). Species determination was carried out in duplicate by multiplex PCR amplification of IS6110, 65kDa, DNAJ (Bahttacharya et al. 2003) and RFLP from hsp65 (Telenti et al. 1993). Reference band patterns were generated using M. tuberculosis (H37Rv strain), Mycobacterium bovis, Mycobacterium avium, Mycobacterium smegmatis, Mycobacterium affricanum, Mycobacterium canetti and M. tuberculosis (Beijing strain).

Amplification of rpoB and katG genes - Multiplex PCR was carried out in $100 \mu \mathrm{L}$ reactions containing $50 \mathrm{mM} \mathrm{KCl}, 10 \mathrm{mM}$ Tris (pH 8.0), $25 \mathrm{mM} \mathrm{MgCl}_{2}, 10$ mM deoxynucleoside 3' -phosphates (dNTPs), 2U Taq polymerase (Promega Madison, WI), $5 \mathrm{nM}$ of an rpoB primer set, $4 \mathrm{nM}$ of a kat $\mathrm{G}$ primer set (Table I) and 300 ng chromosomal DNA from each isolate. Samples were then subjected to one cycle at $95^{\circ} \mathrm{C}$ for $30 \mathrm{~s}$, followed by 35 cycles at $94^{\circ} \mathrm{C}$ for $1 \mathrm{~min}, 65^{\circ} \mathrm{C}$ for $1 \mathrm{~min}, 72^{\circ} \mathrm{C}$ for $1.3 \mathrm{~min}$ and a final elongation cycle at $72^{\circ} \mathrm{C}$ for $5 \mathrm{~min}$. PCR products were electrophoretically separated on a $2 \%$ agarose gel containing ethidium bromide and examined for the presence of the 280-bp and 580-bp bands indicative of the rpoB and $k a t G$ products, respectively. The amplicons of interest were excised from the agarose gel and purified using the mini-elute gel extraction kit (Qiagen, Hilden, Germany) according to the manufacturer's instructions.

DNA sequencing and analysis - The PCR primer sets (Table I) amplify the 81-bp hot-spot region of $r p o B$, including codon 531 and codons 240-390 of katG, including codon 315 . DNA sequencing was carried out in an ABI Prism 7500 capillary sequencer (Applied Biosystems, Foster City, CA, USA) employing a Big Dye terminator cycle sequencing kit (Applied Biosystems). DNA sequence analysis and comparisons of $r p o B$ and kat $G$ were carried out with Chromas V.2.3 and ClustalV programs. The rpoB and kat $G$ sequences from $M$. tuberculosis H37Rv strain, GenBank accession reference numbers 888164 and X68801, respectively, were used to construct the alignment.
TABLE I

Primers used for the amplification of $r p o B$ and $k a t G$

\begin{tabular}{lcc}
\hline Genes & Primer sequence $\left(5^{\prime}-3^{\prime}\right)$ & $\begin{array}{c}\text { Amplicon size } \\
(\mathrm{pb})\end{array}$ \\
\hline rpoB-F & AGCGGATGACCACCCAGGAC & 280 \\
rpoB-R & TCAGGGGTTTCGATCGGGCA & \\
kat $G$-F & GCAGATGGGGCTGATCTACG & 580 \\
kat -R & AACTCGTCGGCCAATTCCTC & \\
\hline
\end{tabular}

\section{RESULTS}

Characterization of clinical isolates - Twenty five clinical isolates were collected from February-July, 2007. Following the Telenti protocol (Telenti et al. 1993), all were shown to have the band profile from the Mycobacterium complex. However, according to the Bahttacharya procedure (Bahttacharya et al. 2003), isolate 67 did not fit into any category and isolate 497 displayed the $M$. bovis profile band. Biochemical probes were inconclusive, therefore both isolates were denominated Mycobacterium spp.

Five of the isolates $(20 \%)$ were drug susceptible, 20 $(80 \%)$ were resistant to at least one drug and $11(44 \%)$ were resistant to four or more drugs. Fifteen isolates $(60 \%)$ were Rif, $17(68 \%)$ were Iso $^{\mathrm{r}}$ and $15(60 \%)$ were Rif $^{\mathrm{r}}$ and $\mathrm{Iso}^{\mathrm{r}}$, that is, MDR (Table II). Identical results were obtained with duplicate samples.

Mutations in rpoB and katG genes - Mutations in the hot-spot of $r p o B$ were detected in $14(93 \%)$ isolates, with each also displaying MDR. No mutations were observed in the Mycobacterium spp isolate (IN: 497). Eleven isolates showed only one mutation (IN: $11,12,53,54,63$, $78,109,123,444,481,535)$, two presented two mutations (IN: 409 and 526) and only one isolate displayed three mutations (IN: 59). Two Rif's isolates (IN: 30, 88) had one mutation.

Regarding the kat $G$ sequenced region (codons 240390 ), mutations in the region encompassing codons $305-$ 328 were detected in $10(58 \%)$ of the $17 \mathrm{Iso}^{\mathrm{r}}$ isolates. Six isolates manifested only one mutation (IN: $12,26,53$, 78,481 and 526), three isolates had two mutations (IN: 11, 497 and 535), one had three mutations (IN: 409) and, finally, one $\mathrm{Iso}^{\mathrm{r}}$-sensitive $\left(\mathrm{Iso}^{\mathrm{s}}\right)$ isolate exhibited three mutations (IN: 524).

Mutations in both genes were observed in only eight (IN: 11, 12, 53, 78, 409, 497, 526 and 535) of the 20 resistant isolates. The eight isolates displayed MDR and were resistant to four or more drugs, except isolate IN: 78, which was exclusively Iso $^{r}$ and Rif: Of the 25 isolates analyzed for mutation in $r p o B$ fragments, seven had mutations at codon 531 TCG (S). Five of those mutations changed the codon to TTG (L) and the other two resulted in a TGG $(\mathrm{W})$ codon. Codon $526 \mathrm{CAC}(\mathrm{H})$ showed two different mutations, GAC (D) in two isolates (IN:63 and 123) and TGC (C) in isolate IN: 12 . Codon 516 GAC (D) displayed the change TAC (Y) in isolate IN: 54 and GTC (V) in isolate IN: 535. Codon $510 \mathrm{CAG}(\mathrm{Q})$ presented the change AAG (K) in isolates IN: 59 and IN: 409. Sin- 
TABLE II

Drug profile and mutations found in rpoB and $k a t G$ genes in 25 Mycobacterium isolates from Veracruz Mexico determined by BACTEC

\begin{tabular}{|c|c|c|c|c|c|c|c|}
\hline \multirow[b]{2}{*}{ Isolate } & \multirow[b]{2}{*}{$\begin{array}{c}\text { Drug resistance } \\
\text { profile }\end{array}$} & \multicolumn{3}{|c|}{ rpoB gene } & \multicolumn{3}{|c|}{$k a t G$ gene } \\
\hline & & Codon & $\begin{array}{c}\text { AA } \\
\text { change }\end{array}$ & $\begin{array}{l}\text { Nucleotide } \\
\text { change }\end{array}$ & Codon & $\begin{array}{c}\text { AA } \\
\text { change }\end{array}$ & $\begin{array}{l}\text { Nucleotide } \\
\text { change }\end{array}$ \\
\hline 55 & $\mathrm{~N}$ & - & - & - & - & - & - \\
\hline 58 & $\mathrm{~N}$ & - & - & - & - & - & - \\
\hline 30 & $\mathrm{~N}$ & $522^{a}$ & $\mathrm{~S} \rightarrow \mathrm{F}$ & TCG-TTC & - & - & - \\
\hline 88 & $\mathrm{~N}$ & $521^{a}$ & $\mathrm{~L} \rightarrow \mathrm{P}$ & CTG-CCT & - & - & - \\
\hline \multirow[t]{3}{*}{524} & $\mathrm{~N}$ & - & - & - & 311 & $\mathrm{D} \rightarrow \mathrm{E}$ & GAC-GAG \\
\hline & & - & - & - & 312 & $A \rightarrow R$ & GCG-CGA \\
\hline & & - & - & - & 335 & $\mathrm{I} \rightarrow \mathrm{I}$ & ATC-ATA \\
\hline 114 & $\mathrm{E}$ & - & - & - & - & - & - \\
\hline 122 & $\mathrm{E}$ & - & - & - & - & - & - \\
\hline 67 & $\mathrm{SE}$ & - & - & - & - & - & - \\
\hline 90 & IE & - & - & - & - & - & \\
\hline \multirow[t]{3}{*}{59} & IR & $510^{a}$ & $\mathrm{Q} \rightarrow \mathrm{K}$ & CAG-AAG & - & - & - \\
\hline & & $517^{a}$ & $\mathrm{Q} \rightarrow \mathrm{L}$ & CAG-CTA & - & - & - \\
\hline & & 531 & $\mathrm{~S} \rightarrow \mathrm{W}$ & TCG-TGG & - & - & - \\
\hline 78 & IR & $524^{a}$ & $\mathrm{~L} \rightarrow \mathrm{S}$ & TTG-TCG & 315 & $\mathrm{~S} \rightarrow \mathrm{T}$ & AGC-ACC \\
\hline 444 & IR & 531 & $\mathrm{~S} \rightarrow \mathrm{W}$ & TCG-TGG & - & - & - \\
\hline 26 & SIE & - & - & - & 315 & $\mathrm{~S} \rightarrow \mathrm{T}$ & AGC-ACC \\
\hline \multirow[t]{2}{*}{497} & SIR & - & - & - & 315 & $\mathrm{~S} \rightarrow \mathrm{T}$ & AGC-ACC \\
\hline & & - & - & -- & 331 & $\mathrm{~S} \rightarrow \mathrm{C}$ & AGT-TGT \\
\hline 481 & SIRE & 531 & $\mathrm{~S} \rightarrow \mathrm{L}$ & TCG-TTG & 328 & $\mathrm{~W} \rightarrow \mathrm{C}$ & TGG-TGC \\
\hline 63 & IREP & 526 & $\mathrm{H} \rightarrow \mathrm{D}$ & CAC-GAC & - & - & - \\
\hline 53 & IREP & 531 & $\mathrm{~S} \rightarrow \mathrm{L}$ & TCG-TTG & 315 & $\mathrm{~S} \rightarrow \mathrm{T}$ & AGC-ACC \\
\hline \multirow[t]{2}{*}{535} & IREP & 516 & $\mathrm{D} \rightarrow \mathrm{V}$ & GAC-GTC & 315 & $\mathrm{~S} \rightarrow \mathrm{T}$ & AGC-ACC \\
\hline & & - & - & - & 316 & $\mathrm{G} \rightarrow \mathrm{G}$ & GGC-GGT \\
\hline \multirow[t]{3}{*}{409} & IREP & $510^{a}$ & $\mathrm{Q} \rightarrow \mathrm{K}$ & CAG-AAG & 311 & $\mathrm{D} \rightarrow \mathrm{E}$ & GAC-GAG \\
\hline & & 531 & $\mathrm{~S} \rightarrow \mathrm{L}$ & TCG-TTG & 312 & $\mathrm{~A} \rightarrow \mathrm{A}$ & GCG-GCA \\
\hline & & - & - & - & 315 & $\mathrm{~S} \rightarrow \mathrm{T}$ & AGC-ACC \\
\hline 12 & SIREP & 526 & $\mathrm{H} \rightarrow \mathrm{C}$ & CAC-TGC & 315 & $\mathrm{~S} \rightarrow \mathrm{T}$ & AGC-ACC \\
\hline \multirow[t]{2}{*}{11} & SIREP & 531 & $\mathrm{~S} \rightarrow \mathrm{L}$ & TCG-TTG & 315 & $\mathrm{~S} \rightarrow \mathrm{T}$ & AGC-ACC \\
\hline & - & - & - & - & 318 & $\mathrm{E} \rightarrow \mathrm{V}$ & GAG-GTA \\
\hline 54 & SIREP & 516 & $\mathrm{D} \rightarrow \mathrm{Y}$ & GAC-TAC & - & - & - \\
\hline 109 & SIREP & $528^{a}$ & $\mathrm{R} \rightarrow \mathrm{P}$ & CGC-CCT & - & - & - \\
\hline 123 & SIREP & 526 & $\mathrm{H} \rightarrow \mathrm{D}$ & CAC-GAC & - & - & - \\
\hline \multirow[t]{2}{*}{526} & SIREP & 509 & $\mathrm{~S} \rightarrow \mathrm{Q}$ & AGC-CAG & 315 & $\mathrm{~S} \rightarrow \mathrm{T}$ & AGC-ACC \\
\hline & & 531 & $\mathrm{~S} \rightarrow \mathrm{L}$ & TCG-TTG & - & - & - \\
\hline
\end{tabular}

a: novel mutations in rpoB; E: ethambutol; I: isoniazid; N: susceptible strain to all drugs; P: pyrazinamide; R: rifampin; S: streptomycin.

gle, double and triple mutations were observed in different isolates at different codons, such as 509 AGC (S) to $\mathrm{CAG}(\mathrm{Q}), 517 \mathrm{CAG}(\mathrm{Q})$ to CTA (L), $524 \mathrm{TTG}(\mathrm{L})$ to TCG (S) and 528 CGC (R) to CCT (P). Finally, two Rif ${ }^{\mathrm{s}}$ isolates (IN: 88 and IN: 30 ) were mutated at codon 521 CTG (L) to CCT (P) and at codon 522 TCG (S) to TTC (F), respectively (Table II).

Of the 25 isolates, only nine Iso ${ }^{\mathrm{r}}$ from the $k a t G$ sequenced fragment presented mutations at codon 315 changing AGC (S) to ACC (T). Codon 311 GAC (D) exhibited the mutation GAG (E) in Iso ${ }^{\mathrm{r}}$ IN: 409 and IN: $524 \mathrm{Iso}^{\mathrm{s}}$ isolates. Codon $312 \mathrm{GCG}(\mathrm{A})$ presented two changes, a silent mutation GCA (A) in isolate 409 and CGA (R) in the Iso ${ }^{\mathrm{s}}$ isolate 524. Changes at codons 318 GAG (E) and 331 AGT (S) to GTA (V) and TGT (C) were observed in Iso $^{\mathrm{r}}$ isolates IN: 11 and IN: 497, respectively. Finally, codon 335 ATC (I) showed the silent mutation ATA (I) in Iso ${ }^{\mathrm{s}}$ isolate 524.

\section{DISCUSSION}

Despite the narrow window of specimen collection and the scarcity of clinical isolates, we were able to analyze 20 DR-TB isolates, which approximates the $15 \%$ of the DR-TB isolates reported annually by the public health services of Veracruz. It is important to mention that 18 isolates $(90 \%)$ were resistant to more than one drug and $15(75 \%)$ were MDR-TB. These percentages contrast with the 1997 national surveillance on DR-TB, in which prevalences of $21.5 \%$ for one drug, $7.4 \%$ for MDR and 2.6\% for five or more drugs were recorded 
(Granich et al. 2000). The 2008 DR-TB national surveillance will help to obtain a clearer understanding of the true status and evolution of this public health problem (NSTBDR 2008).

Most of the mutations reported worldwide in the rроB gene of Mycobacterium occur at codons 526 and 531 (Huang et al. 2002, Sajduda et al. 2004, Hillemann et al. 2005, Höfling et al. 2005); indeed, mutations at these sites explain $85-95 \%$ of Rif ${ }^{\prime}$ cases. However, these mutations only explain $65 \%$ of our Rif isolates: $18 \%(n=3)$ for 526 and $47 \%(n=7)$ for 531 . Several mutations found in our isolates are in agreement with previous reports of isolates from the north and centre of Mexico (Alvarado et al. 2001, Bobadilla del Valle et al. 2001, Viader-Salvado et al. 2003, Ramaswamy et al. 2004) and other countries (Huang et al. 2002, Sajduda et al. 2004, Hillemann et al. 2005, Höfling et al. 2005). However, five novel mutations were found in Rif ${ }^{\mathrm{r}}$ isolates. Two of these resulted in a single nucleotide change, 510 (CAG-AAG, $\rightarrow \mathrm{K}$ ) and 524 (TTG-TCG, $\mathrm{L} \rightarrow \mathrm{S}$ ), while three mutations contained double nucleotide changes, 517 (CAG-CTA, Q $\rightarrow$ L), 521 $(\mathrm{CTG}-\mathrm{CCT}, \mathrm{L} \rightarrow \mathrm{P})$ and $526(\mathrm{CAC}-\mathrm{TGC}, \mathrm{H} \rightarrow \mathrm{C})$. Additionally, two new mutations were observed in $\mathrm{Rif}^{\mathrm{s}}$ isolates, 528 (CGC-CCT, R $\rightarrow$ P) and 522 (TCG-TTC, S $\rightarrow$ F). The effect of these new mutations on protein functionality should be carefully evaluated.

According to Telenti's procedure (Telenti et al. 1993), two isolates were shown to pertain to the $M$. tuberculosis complex. However, using Bahttacharya's assay (Bahttacharya et al. 2003), isolate 67 did not fit into any category and isolate 497 exhibited an M. bovis profile. Some doubts arise from the latter assay given that both isolates grew properly in Löwestein-Jensen medium and no pyrazinamide resistance was detected. Moreover, biochemical probe analysis for both isolates were inconclusive. Furthermore, both isolates have specific drug resistance profiles. Isolate 67 showed a unique combined resistance to streptomycin and ethambutol while isolate 497 presented resistance to streptomycin, Iso and Rif. Analysis of the $k a t G$ gene displayed two mutations, one at codon 315 and the second at codon 331. This last mutation was not observed in the remainder of the analyzed isolates. On the other hand, no mutations were observed in the $r p o B$ gene. A similar result was previously reported in other Rif isolates, with the mutations being located outside the RRDR (Heep et al. 2000, 2001). Currently, we are working on identifying mutations in the complete rро $B$ gene from isolate 497 . In order to obtain the correct species assignment, we are attempting to sequence the $16 \mathrm{~S}$ rDNA gene of both atypical isolates.

Isolate 30 was reported as $\mathrm{Rif}^{\mathrm{s}}$, however, a mutation was found at codon 522 (TCG-TTC, $\mathrm{S} \rightarrow \mathrm{F}$ ). A similar mutation at this codon $(\mathrm{S} \rightarrow \mathrm{L})$ was recently reported to correlate with a low level of resistance in clinical isolates and to be associated with a bacterial fitness deficit (Mariam et al. 2004, Huitric et al. 2006). Thus, this isolate could help in understanding the real value of this codon change in the biology of Mycobacterium and the sensitivity of the BACTEC system for the diagnosis of DR-TB. At present, we are determining the minimal inhibitory concentration of this isolate via the microplate alamar blue assay.
Concerning Iso ${ }^{\mathrm{r}}$ resistance, mutation at codon 315 in $k a t G$ explains only $52 \%(\mathrm{n}=9)$ of the $17 \mathrm{Iso}^{\mathrm{r}}$ isolates analyzed. Hence, the frequency of this mutation may vary according to geographical area, even within a single country. In agreement with our data, others have reported that $64 \%$ of 70 isolates from India have this mutation (Nusrath et al. 2008), as well as $62 \%$ of 79 isolates from Spain (Torres et al. 2002) and 53\% of 67 isolates from the North of Mexico (Viader-Salvadó et al. 2003). In partial agreement, others have found that $67 \%$ of 37 isolates from the North of Mexico have this mutation (Ramaswamy et al. 2004), as well as $69 \%$ of 105 isolates from Poland (Sajduda et al. 2004) and $72 \%$ of 69 isolates from Brazil (Silva et al. 2003). Finally, in another study, no variability was observed in the mutation frequency of codon 315; a mutation was observed in $100 \%$ of 92 isolates from Kazahastan, Belarus (Hilleman et al. 2005). Hence, this mutation needs to be analyzed in a local context, not by international comparison.

It is possible that mutations in other genomic regions, such as the mabA-inhA intergenic region, the inhA and the kasA genes (Musser 1995, Zhang \& Telenti 2000), may contribute significantly to $\mathrm{Iso}^{\mathrm{r}}$ resistance in the isolates from the southern part of the country. It is interesting to note that six additional mutations were identified in the $k a t G$ region of Isor isolates. Three of these mutations, one at codon 328 and two nonsense mutations at codons 312 and 316, have been previously reported (Nusrath et al. 2008, Bostanabad et al. 2008), while three others were novel observations (codons 311, 318 and 331). However, all isolates contain mutations to codon 315 , except for a nonsense mutation at codon 335 in an Iso isolate (IN: 524) and at codon 328 in an Iso ${ }^{\mathrm{r}}$ isolate (IN: 328). Thus, the role these mutations might play in inducing conformational changes in $\mathrm{katG}$ or inhibiting $\mathrm{Iso}^{\mathrm{r}}$ binding, resulting in $\mathrm{Iso}^{\mathrm{r}}$ resistance, is uncertain and needs to be evaluated in detail.

Understanding the nature and frequency of mutations associated with DR-TB in different settings is important for the development of genetic-based assays useful for the detection of drug resistance on a large-scale (Pai et al. 2006). In this study, mutations in $r p o B$ codon 531 and in $k a t G$ codon 315 were identified only in $47 \%$ of the Rif and $63 \%$ of the Iso ${ }^{\mathrm{r}}$ collected isolates, respectively. Furthermore, each isolate showed a particular mutational pattern. These data need to be considered if a genetic-based diagnosis of DR-TB is to be developed for the region. Additionally, these data are indicative of a high heterogeneity of DR-TB isolates present among the population, possibly exacerbated by inappropriate clinical management of patients. Genotyping and epidemiological studies are in progress in order to confirm this hypothesis.

In conclusion, this is, to our knowledge, the first report of mutations at $k a t G$ and rpoB genes from sensitive and drug resistant Mycobacterium isolates from the South of Mexico, a regional source of a large number of immigrant workers within the United States of America. At present, we are collecting additional DR-TB isolates and increasing the number of genes that will be analyzed in order to identify mutations associated with first and second line drugs. This information will help us to cre- 
ate a better and more detailed description of the DR-TB isolates moving among the population and to improve molecular strategies for their diagnosis and control.

\section{REFERENCES}

Alvarado-Esquivel C, Rossau R, Martínez-García S, Cisneros-Martínez JA, Mijs W, Nevárez-Nájera A, Fierro-Campa R, MercadoSuárez MF, Hernández-Campos S, Chacón-Arciniega R, Vázquez J, Saucedo-Martínez G, Ruiz-Astorga R 2001. Characterization of rpoB gene mutations in rifampin resistant Mycobacterium tuberculosis strains isolated from pulmonary tuberculosis patients at 5 Mexican public hospitals. Rev Invest Clin 53: 526-530.

Bahttacharya B, Karak K, Ghosal AG, Roy A, Das S, Dandapat P, Khetawat D, Mondal DK, Bhattacharya S, Chakrabarti S 2003. Development of a new sensitive and efficient multiplex polymerase chain reaction (PCR) for identification and differentiation of different mycobacterial species. Trop Med Int Health 8: 150-157.

Bobadilla del Valle M, Ponce-de-Leon A, Arenas-Huertero C, VargasAlarcon G, Kato-Maeda M, Small PM, Couary P, Ruiz-Palacios GM, Sifuentes-Osornio J 2001. rpoB gene mutations in rifampinresistant Mycobacterium tuberculosis identified by polymerase chain reaction single-stranded conformational polymorphism. Emerg Infect Dis 7: 1010-1013.

Bostanabad SZ, Titov LP, Bahrmand A, Nojoumi SA 2008. Detection of mutation in isoniazid-resistant Mycobacterium tuberculosis isolates from tuberculosis patients in Belarus. Indian J Med Microbiol 26: 143-147.

Dye C, Scheele S, Dolin P, Pathania V, Raviqlione MC 1999. Global burden of tuberculosis: estimated incidence, prevalence and mortality by country. WHO global surveillance and monitoring project. JAMA 282: 677-686.

Granich RM, Balandrano S, Santaella AJ, Binkin NJ, Castro KG, Marquez-Fiol A, Anzaldo G, Zarate M, Jaimes ML, VelazquezMonroy O, Salazar L, Alvarez-Lucas C, Kuri P, Flisser A, SantosPreciado J, Ruiz-Matus C, Tapia-Conyer R, Tappero JW 2000. Survey of drug resistance of Mycobacterium tuberculosis in 3 Mexican states, 1997. Arch Intern Med 2000 160: 639-644.

Heep M, Brandstätter B, Rieger U, Lehn N, Richter E, Rüsch-Gerdes $\mathrm{S}$, Niemann S 2001. Frequency of $r$ poB mutations inside and outside the cluster I region in rifampin-resistant clinical Mycobacterium tuberculosis isolates. J Clin Microbiol 39: 107-110.

Heep M, Rieger U, Beck D, Lehn N 2000. Mutations in the beginning of the rpoB gene can induce resistance to rifamycins in both $\mathrm{He}$ licobacter pylori and Mycobacterium tuberculosis. Antimicrob Agents Chemother 44: 1075-1077.

Hillemann D, Kubica T, Agzamova R, Venera B, Rüsch-Gerdes S, Niemann S 2005. Rifampicin and isoniazid resistance mutations in Mycobacterium tuberculosis strains isolated from patients in Kazakhstan. Int J Tuberc Lung Dis 9: 1161-1167.

Höfling CC, Pavan EM, Giampaglia CM, Ferrazoli L, Aily DC, de Albuquerque DM, Ramos MC 2005. Prevalence of katG Ser315 substitution and rpoB mutations in isoniazid-resistant Mycobacterium tuberculosis isolates from Brazil. Int J Tuberc Lung Dis 9: 87-93.

Huang H, Jin Q, Ma Y, Chen X, Zhuang Y 2002. Characterization of rроB mutations in rifampicin-resistant Mycobacterium tuberculosis isolated in China. Tuberculosis 82: 79-83.

Huitric E, Werngren J, Juréen P, Hoffner S 2006. Resistance levels and $r р о B$ gene mutations among in vitro-selected rifampin-resistant Mycobacterium tuberculosis mutants. Antimicrob Agents Chemother 50: 2860-2862.
Mariam DH, Mengistu Y, Hoffner SE, Andersson DI 2004. Effect of $r p o B$ mutations conferring rifampin resistance on fitness of Mycobacterium tuberculosis. Antimicrob Agents Chemother 48: 1289-1294.

Musser JM 1995. Antimicrobial agent resistance in mycobacteria: molecular genetic insights. Clin Microbiol Rev 8: 496-514.

NSTBDR - National Survey on TB drug-resistance, Mexico. Encuesta Nacional de Farmacorresistencia en tuberculosis, México 2008. PAHO/INDRE, México [update 12 July 2008]. Available from: http://www.mex.ops-oms.org/contenido/tuberculosis/encuesta/.

Nusrath-Unissa A, Selvakumar N, Narayanan S, Narayanan PR 2008. Molecular analysis of isoniazid-resistant clinical isolates of Mycobacterium tuberculosis from India. Int J Antimicrob Agents 31: 71-75.

Pai M, Kalantri S, Dheda K 2006. New tools and emerging technologies for the diagnosis of tuberculosis: part II. Active tuberculosis and drug resistance. Expert Rev Mol Diagn 6: 423-432.

Programa Estatal de Tuberculosis. Servicios de Salud de Veracruz, México [update 25 November 2008]. Available from: http://sesver. ssaver.gob.mx/portal/page?_pageid $=693,6992673 \& \_d a d=$ portal\& schema $=$ PORTAL .

Ramaswamy SV, Dou SJ, Rendon A, Yang Z, Cave MD, Graviss EA 2004. Genotypic analysis of multidrug-resistant Mycobacterium tuberculosis isolates from Monterrey, Mexico. J Med Microbiol 53: 107-113.

Sajduda A, Brzostek A, Poplawska M, Augustynowicz-Kopec E, Zwolska Z, Niemann S, Dziadek J, Hillemann D 2004. Molecular characterization of rifampin and isoniazid-resistant Mycobacterium tuberculosis strains isolated in Poland. J Clin Microbiol 42: 2425-2431.

Sambrook J, Fritsch F, Maniatis T 1989. Molecular cloning: a laboratory manual, Cold Springs Harbor Laboratory Press New York, New York, 999 pp.

Silva M, Senna S, Ribeiro M, Valim A, Telles MA, Kritski A, Morlock GP, Cooksey RC, Zaha A, Rossetti ML 2003. Mutations in katG, inhA and $a h p C$ genes of Brazilian isoniazid-resistant isolates of Mycobacterium tuberculosis. J Clin Microbiol 41: 4471-4474.

Telenti A, Marchesi F, Balz M, Bally F, Bottger E, Bodmer T 1993. Rapid differentiation of mycobacteria to the species level by polymerase chain reaction and restriction enzyme analysis. J Clin Microbiol 31: 175-178.

Torres M, Criado A, Gónzalez N, Palomares JC, Aznar J 2002. Rifampin and isoniazid resistance associated mutations in Mycobacterium tuberculosis clinical isolates in Seville, Spain. Int $J$ Tuberc Lung Dis 6: 160-163.

Viader-Salvadó JM, Luna-Aguirre CM, Reyes-Ruiz JM, Valdez-Leal $\mathrm{R}$, del Bosque-Moncayo M de L, Tijerina-Menchaca R, Guerrero-Olazarán M 2003. Frequency of mutations in $r p o B$ and codons 315 and 463 of $k a t G$ in Rif $^{\mathrm{r}}$ and/or Iso ${ }^{\mathrm{r}}$ isoniazid-resistant Mycobacterium tuberculosis isolates from Northeast Mexico. Microb Drug Resist 9: 33-38.

WHO - World Health Organization 2006. Global tuberculosis control: surveillance, planning, financing, WHO Report 2006, Geneva, p. 83-85.

Zhang Y, Telenti A 2000. Genetics of drug resistance in Mycobacterium tuberculosis. In GF Hatfull, WR Jacobs (eds.), Molecular genetics of mycobacteria, ASM Press, Washington DC, p. 235-254.

Zumia A, Grange JM 2001. Multidrug-resistant tuberculosis can the tide be turned? Lancet Infect Dis 1: 199-202. 